\title{
Second Heart Sound in Normal Subjects
}

\author{
ALAN HARRIS AND GEORGE SUTTON* \\ From St. George's Hospital, London S.W.1
}

Splitting of the second heart sound in the pulmonary area into two components was first recognized by Potain (1866). In expiration, the two components fuse, while in inspiration delay of pulmonary valve closure $\left(\mathrm{P}_{2}\right)$ occurs almost invariably in healthy subjects, enabling identification of aortic valve closure $\left(A_{2}\right)$ and $P_{2}$, and hence comparison of the duration of right and left ventricular systole (Leatham and Towers, 1951). Knowledge of splitting of the second sound has proved an essential part of auscultation of the heart, and greatly facilitates the bedside diagnosis of atrial septal defect and pulmonary stenosis, physiological murmur, conduction defects, and ventricular function (Leatham, 1964).

Detailed analyses of the second heart sound $\left(S_{2}\right)$ in normal subjects have been made by several authors, including Boyer and Chisholm (1958), Shafter (1960), Castle and Jones (1961), and Aygen and Braunwald (1962). The main emphasis has been upon an analysis of the splitting of $S_{2}$ during respiration into its two components. The groups investigated have been children or young adults. Though these authors have shown that $\mathrm{A}_{2}$ becomes earlier and $P_{2}$ later at the beginning of inspiration, there has been disagreement about the relative contribution of each of these events to the width of splitting of $S_{2}$.

In this study the second heart sound has been analysed by phonocardiography in a number of normal subjects of different age-groups, from infancy to old age. The relative intensities of $A_{2}$ and $P_{2}$ in the pulmonary area, and the frequency of transmission of $P_{2}$ to the mitral area have received particular attention, since in heart disease these characteristics may be altered. In addition we have reinvestigated the splitting of $S_{2}$ to establish normal values in different age-groups.

Received January 10, 1968.

^ Present address: Brompton Hospital, London S.W.3.

\section{SUBJECTS AND METHODS}

Phonocardiograms were obtained in 162 normal subjects, ages ranging from 1-80 years. Suction microphones were placed in the pulmonary and mitral areas, with the subject at rest in the supine position at $45^{\circ}$. The paper speed was $100 \mathrm{~mm}$. per second, and the galvanometer used for sound responded uniformly from 30 to 800 cycles per second (Leatham, 1952). The recordings were made by the Cambridge (England) photographic recorder. All recordings were made during normal continuous respiration simultaneously with lead II of the electrocardiogram and external carotid trace in order to identify $A_{2}$ by means of the dicrotic notch.

The following measurements were made from each recording over three respiratory cycles:

(1) The width of splitting of $S_{2}$ in expiration.

(2) The width of splitting of $S_{2}$ in inspiration.

(3) The movement of $A_{2}$ from the onset of electrical activity $(Q)$ during respiration, representing the variation in duration of left ventricular systole.

(4) The ratio of the intensity of $A_{2}$ to $P_{2}$ in the pulmonary area graded as greater than 2:1, greater than 1:1 and less than $2: 1$, and less than $1: 1$.

(5) The presence or absence of $P_{2}$ in the mitral area.

Measurements of $\mathrm{Q}-\mathrm{A}_{2}$, and $\mathrm{Q}-\mathrm{P}_{2}$ (representing the variation in duration of right ventricular systole) were made to the nearest $0.01 \mathrm{sec}$. From these measurements, the contribution of the movement of $\mathrm{A}_{2}$ during respiration to the width of splitting of $S_{2}$ was calculated as a percentage. The findings were divided into 5 groups according to the age of each subject: 1-5, 5-10, $10-20,20-40$, and $40-80$ years.

\section{RESULTS}

The findings are summarized in the Table.

Age-group 1-5 years (30 subjects). $\mathrm{S}_{2}$ was single in expiration in 28 subjects ( 93 per cent). There were no instances of an expiratory split of greater than $0.02 \mathrm{sec}$. The range of inspiratory splitting varied from $0.02-0.05 \mathrm{sec}$., and 66 per cent of the variation in split was due to movement of $\mathrm{P}_{2} \cdot \mathbf{Q}-\mathrm{A}_{2}$ remained constant during respiration in 5 subjects, shortened by $0.01 \mathrm{sec}$. in inspiration in 20 subjects 
TABLE

ANALYSIS OF SECOND HEART SOUND BY AGE-GROUPS IN NORMAL SUBJECTS

\begin{tabular}{|c|c|c|c|c|c|c|}
\hline Age-group (yr.) & $1-5$ & $5-10$ & $10-20$ & $20-40$ & $40-80$ & Over-all \\
\hline No. of subjects & 30 & 35 & 52 & 23 & 22 & 162 \\
\hline Single $S_{2}$ in expiration & $28(93)^{\star}$ & $30(86)$ & $44(85)$ & $23(100)$ & $20(91)$ & $145(90)$ \\
\hline$S_{2}$ split 0.02 sec. in expiration & 0 & $1(3)$ & $2(4)$ & 0 & 0 & $3(2)$ \\
\hline $\begin{array}{l}\text { Inspiratory split of } S_{2} \text { (sec.) } \\
0,0.01 \\
0.02 \\
0.03 \\
0.04 \\
0.05 \\
0.06\end{array}$ & $\begin{array}{l}0 \\
7(23) \\
10(33) \\
10(33) \\
3(10) \\
0\end{array}$ & $\begin{array}{r}0 \\
4(11) \\
11(32) \\
11(32) \\
5(14) \\
4(11)\end{array}$ & $\begin{array}{l}0 \\
1(2) \\
15(29) \\
25(48) \\
11(21) \\
0\end{array}$ & $\begin{array}{l}1(4) \\
3(13) \\
3(13) \\
8(35) \\
6(26) \\
2(9) \\
\end{array}$ & $\begin{array}{l}6(27) \\
4(18) \\
7(32) \\
3(14) \\
2(9) \\
0\end{array}$ & $\begin{array}{c}7(4) \\
19(12) \\
46(28) \\
47(29) \\
34(21) \\
6(4) \\
\end{array}$ \\
\hline $\begin{array}{l}\text { Movement of } \mathrm{Q}-\mathrm{A}_{2} \text { in inspiration (sec.) } \\
\quad 0 \\
-0.01 \\
-0.02 \\
+0.01\end{array}$ & $\begin{array}{r}5(16) \\
20(66) \\
5(16) \\
0\end{array}$ & $\begin{array}{c}8(23) \\
26(74) \\
0 \\
1(3)\end{array}$ & $\begin{array}{r}5(10) \\
41(79) \\
6(11) \\
0\end{array}$ & $\begin{array}{r}4(17) \\
16(70) \\
3(13) \\
0\end{array}$ & $\begin{array}{c}8(36) \\
13(59) \\
1(5) \\
0\end{array}$ & $\begin{array}{r}30(19) \\
116(72) \\
15(9) \\
1(1) \\
\end{array}$ \\
\hline $\begin{array}{l}\text { Average contribution of } \mathrm{A}_{2} \text { movement } \\
\text { in width of splitting of } \mathrm{S}_{2}\end{array}$ & 34 & 25 & 30 & 21 & 36 & 29 \\
\hline $\begin{array}{l}\text { Relative intensity of } A_{2}: P_{2} \text { in pul- } \\
\text { monary area } \\
>2: 1 \\
>1: 1 \\
<1: 1 \\
\text { Not certain }\end{array}$ & $\begin{array}{c}20(66) \\
9(30) \\
1(3) \\
0\end{array}$ & $\begin{array}{c}21(60) \\
13(37) \\
1(3) \\
0\end{array}$ & $\begin{array}{c}30(58) \\
21(40) \\
1(2) \\
0\end{array}$ & $\begin{array}{r}14(61) \\
9(39) \\
0 \\
0\end{array}$ & $\begin{array}{r}6(27) \\
10(46) \\
0 \\
6(27) \\
\end{array}$ & $\begin{array}{c}91(56) \\
62(38) \\
3(2) \\
6(4) \\
\end{array}$ \\
\hline $\mathbf{P}_{2}$ in mitral area & $3(10)$ & $4(11)$ & $2(4)$ & 0 & 0 & $9(6)$ \\
\hline
\end{tabular}

$\star$ Percentages are in parentheses.

( 66 per cent), and shortened by 0.02 sec. in inspiration in 5 subjects. The contribution of $\mathrm{A}_{2}$ movement to the width of respiratory splitting of $S_{2}$ was an average of 34 per cent.

In 20 subjects $(66 \%)$, the $A_{2}-P_{2}$ ratio in the pulmonary area was greater than $2: 1$, in 9 subjects $(30 \%)$ it was greater than $1: 1$, and in one subject $\mathrm{P}_{2}$ was greater than $\mathbf{A}_{2}$. In this last subject, and in 2 other subjects, $P_{2}$ was recorded in the mitral area.

Age-group 5-10 years (35 subjects). $\mathrm{S}_{2}$ was single in expiration in 30 subjects ( $86 \%$ ). In one instance, the split was wider than $0.02 \mathrm{sec}$. $(0.03 \mathrm{sec}$.) without any evidence of intraventricular conduction defect. The range of inspiratory splitting varied from $0.02-$ 0.06 sec., and 75 per cent of the variation in split was due to movement of $P_{2} . Q-A_{2}$ remained constant during respiration in 8 subjects, and increased in inspiration by $0.01 \mathrm{sec}$. in one subject. The contribution of $\mathrm{A}_{2}$ movement to the width of respiratory splitting of $S_{2}$ was an average of 25 per cent.

In 21 subjects $(60 \%)$, the $A_{2}-P_{2}$ ratio was greater than $2: 1$, in 13 subjects the ratio was greater than $1: 1$, and in one subject $P_{2}$ was greater than $A_{2}$. In this last subject, and in 3 others, $P_{2}$ was recorded in the mitral area.
Age-group 10-20 years (52 subjects). $\mathrm{S}_{2}$ was single in expiration in 44 subjects (85\%). In 2 subjects the split was 0.03 and $0.04 \mathrm{sec}$. in expiration, respectively, without any evidence of intraventricular conduction defect. The range of inspiratory splitting varied from $0.02-0.05$ sec., and 70 per cent of the variation in split was due to movement of $P_{2}$. Q- $\mathrm{A}_{2}$ remained constant during respiration in 5 subjects, shortened by $0.01 \mathrm{sec}$. in inspiration in 41 subjects $(79 \%)$, and shortened by $0.02 \mathrm{sec}$. in inspiration in 6 subjects. The contribution of $\mathrm{A}_{2}$ movement to the width of respiratory splitting of $S_{2}$ was an average of 30 per cent.

In 30 subjects ( $58 \%$ ), the $\mathrm{A}_{2}-\mathrm{P}_{2}$ ratio was greater than $2: 1$, in 21 subjects ( $40 \%$ ) the ratio was greater than $1: 1$, and in one subject $P_{2}$ was greater than $A_{2}$. In this last subject, and in one other, $P_{2}$ was recorded in the mitral area.

Age-group 20-40 years (23 subjects). $\mathrm{S}_{2}$ was single in expiration in all subjects. The range of inspiratory splitting ranged from $0-0.6 \mathrm{sec}$., and 79 per cent of the variation in split was due to movement of $P_{2}$. Q $-A_{2}$ remained constant during respiration in 4 subjects, shortened by $0.01 \mathrm{sec}$. in inspiration in 16 subjects (70\%), and shortened by $0.02 \mathrm{sec}$. in inspiration in 3 subjects. The contribution of $\mathrm{A}_{2}$ movement to the width of respiratory splitting of $S_{2}$ was an average of 21 per cent in this group. 
In 14 subjects (61\%), the $A_{2}-P_{2}$ ratio was greater than $2: 1$, and in 9 subjects (39\%) it was greater than 1:1. There were no instances of $P_{2}$ greater than $A_{2}$. $\quad P_{2}$ was never recorded in the mitral area in this group.

Age-group 40-80 years (22 subjects). $\mathrm{S}_{2}$ was single in expiration in 20 subjects $(91 \%) . \quad S_{2}$ was never split wider than $0.02 \mathrm{sec}$. in expiration. The range of inspiratory splitting varied from $0-0.05$ sec., and 64 per cent of the variation in split was due to movement of $\mathbf{P}_{2}$. Q $\mathbf{Q}-\mathrm{A}_{2}$ remained constant during respiration in 8 subjects (36\%), shortened by $0.01 \mathrm{sec}$. in 13 subjects ( $59 \%$ ), and shortened by $0.02 \mathrm{sec}$. in inspiration in one subject. The contribution of $\mathrm{A}_{2}$ movement to the width of respiratory splitting of $S_{2}$ was an average of 36 per cent in this group.

In 6 subjects $(27 \%)$, the $\mathbf{A}_{2}-\mathbf{P}_{2}$ ratio was greater than $2: 1$, and in 10 subjects $(46 \%)$ it was greater than 1:1. Two distinct components of $S_{2}$ could not be separated in any phase of respiration in 6 subjects, prohibiting comment on relative intensity of $A_{2}$ and $P_{2}$. It was not possible to be certain when $S_{2}$ was single whether the intensity of $P_{2}$ was too low to record, or simply that the two components failed to separate. $\mathbf{P}_{2}$ was never recorded in the mitral area.

\section{Discussion}

Splitting of $S_{2}$. Our results have shown that 90 per cent of normal subjects have a single $S_{2}$ in the pulmonary area in expiration. Expiratory splitting of greater than $0.02 \mathrm{sec}$. was very uncommon (2\%). This is in agreement with Leatham (1954), Shafter (1960), and Castle and Jones (1961). The degree of inspiratory splitting ranged from $0.02-0.06 \mathrm{sec}$., and was less than $0.02 \mathrm{sec}$. in some instances in the 20-80 age-groups, but the most important factor determining the degree of inspiratory splitting is the depth of inspiration which was not studied, so that these values for inspiratory splitting have no special significance. While delay of $P_{2}$ is the main feature in inspiratory splitting of $S_{2}$ (Leatham and Towers, 1951), the movement of $\mathrm{A}_{2}$ during respiration has received considerable comment. Physiological studies (Shuler et al., 1942; Lauson, Bloomfield, and Cournand, 1946) suggested that there was inspiratory shortening of left ventricular systole (which would result in an earlier $\mathbf{A}_{2}$ ). Boyer and Chisholm (1958) analysed phonocardiograms in 20 normal subjects (both young adults and children), and introduced the concept of a lag in the effect of inspiration on left ventricular filling based on the work of Dornhorst, Howard, and Leathart (1952). Castle and Jones
(1961), studying 68 children aged 5-15 years, showed that the movement of $\mathrm{A}_{2}$ contributed, on an average, 35 per cent to the width of splitting of $S_{2}$. Aygen and Braunwald (1962) could not confirm those results in 51 normal subjects, attributing only 14 per cent of the split to movement of $A_{2}$, which agreed with Shuler et al. (1942) who showed that respiratory variations of the stroke volume of the right ventricle exceeded those of the left.

Our findings showed that an average of 29 per cent of the splitting of $S_{2}$ was due to an early $A_{2}$ in inspiration. However, we do not believe this figure to be particularly reliable, as we do not feel that any of those measurements can be made with an accuracy of greater than $0.01 \mathrm{sec}$, even at recording speeds of $100 \mathrm{~mm}$. per sec. In our results a movement of less than $0.01 \mathrm{sec}$. was recorded as 0.01 , and consequently a true figure of less than 29 per cent contribution by $\mathrm{A}_{2}$ movement is probable, and more in agreement with the view of Aygen and Braunwald (1962). A notable feature was that in 19 per cent of all normal subjects there was no detectable movement of $A_{2}$ at all, and this was particularly true of the subjects in the $40-80$ age-group.

Relative intensity of $A_{2}: P_{2}$ in pulmonary area. Little information is available on this aspect of the second heart sound. Leatham, Segal, and Shafter (1963), in a phonocardiographic study of 80 children, noted that $\mathrm{A}_{2}$ was greater than $\mathrm{P}_{2}$ in the pulmonary area in 87 per cent. Ongley et al. (1960) state that the relative intensities of $A_{2}$ and $P_{2}$ vary in different ages in normal subjects, with $P_{2}$ being more noticeable than $A_{2}$ in children, and $A_{2}$ more noticeable than $P_{2}$ in normal adults. Quantitation of the intensity of each component has not been attempted, and it may be that there are too many factors that affect the transmission of heart sounds through the chest wall for this to be feasible. We have simply noted the relative intensities of the two components in the pulmonary area, realizing that we do not know the contribution of each component to this characteristic. Our findings showed that in 94 per cent of all age-groups $A_{2}$ is louder than $P_{2}$, with no significant variation accounted for by age. We have only three instances of $P_{2}$ being louder than $A_{2}$ in the pulmonary area in normal healthy subjects.

$P_{2}$ in mitral area. Figures are not available for comparison with our results, though the statement that the finding of $P_{2}$ in the mitral area is abnormal has been made (Leatham, 1958). We found that our 9 instances of $P_{2}$ in the mitral area occurred in the younger age-groups. This is perhaps not surprising when the proximity of the pulmonary and 
mitral areas in children is considered. Moreover, in the rare instances when $P_{2}$ was greater than $A_{2}$ in the pulmonary area, $P_{2}$ could be recorded in the mitral area.

\section{SUMMARY}

Studies have been made of 162 normal subjects by means of simultaneous phonocardiograms in the pulmonary and mitral areas during continuous respiration. They have been subdivided into 5 groups.

The second heart sound has been studied in terms of several characteristics:

(1) In the expiratory phase of continuous respiration $\mathrm{S}_{2}$ was usually single $(90 \%)$ and was very rarely split by more than $0.02 \mathrm{sec}$. $(2 \%)$.

(2) The inspiratory split of $S_{2}$ varied from $0-0.06$ sec., of which the movement of $\mathrm{Q}-\mathrm{P}_{2}$ contributed the major portion $(71 \%)$. The movement of $\mathrm{Q}-\mathrm{A}_{2}$ contributed at most 29 per cent to this split.

(3) In some instances (19\%) there was no movement of $\mathrm{Q}-\mathrm{A}_{2}$ during respiration.

(4) In the majority of subjects (94\%), $A_{2}$ was greater in intensity than $P_{2}$ in the pulmonary area.

(5) $P_{2}$ was recorded in the mitral area in the 3 subjects where $P_{2}$ was greater than $A_{2}$ in the pulmonary area, and in 9 subjects altogether.

(6) The only variation in these patterns related to age was the occasional recording of $P_{2}$ in the mitral area in children, but never in adults.

\section{REFERENCES}

Aygen, M. M., and Braunwald, E. (1962). The splitting of the second heart sound in normal subjects and in patients with congenital heart disease. Circulation, 25, 328.
Boyer, S. H., and Chisholm, A. W. (1958). Physiologic splitting of the second heart sound. Circulation, 18, 1010.

Castle, R. F., and Jones, K. L. (1961). The mechanism of respiratory variation in splitting of the second heart sound. Circulation, 24, 180.

Dornhorst, A. C., Howard, P., and Leathart, G. L. (1952). Respiratory variations in blood pressure. Circulation, 6, 553.

Lauson, H. D., Bloomfield, R. A., and Cournand, A. (1946). The influence of the respiration on the circulation in man, with special reference to pressures in the right auricle, right ventricle, femoral artery and peripheral veins. Amer. F. Med., 1, 315.

Leatham, A. (1952). Phonocardiography. Brit. med. Bull., 8, 333.

(1954). Splitting of the first and second heart sounds. Lancet, $2,607$.

- (1958). Auscultation of the heart. Lancet, 2, 703.

- (1964). The second heart sound: Key to auscultation of the heart. Acta cardiol. (Brux.), 19, 395.

—, Segal, B. L., and Shafter, H. (1963). Auscultatory and phonocardiographic findings in healthy children with systolic murmurs. Brit. Heart f., 25, 451.

- and Towers, M. (1951). Splitting of the second heart sound in health. In Proceedings of the British Cardiac Society. Brit. Heart F., 13, 575.

Ongley, P. A., Sprague, H. B., Rappaport, M. B., and Nadas, A. S. (1960). Heart Sounds and Murmurs. Grune and Stratton, New York.

Potain, C. (1866). Note sur les dédoublements normaux des bruits du coeur. Bull. Mém. Soc. méd. Hôp. Paris, 2 sér., 3, 138.

Shafter, H. A. (1960). Splitting of the second heart sound. Amer. F. Cardiol., 6, 1013.

Shuler, R. H., Ensor, C., Gunning, R. E., Moss, W. G., and Johnson, V. (1942). The differential effects of respiration on the left and right ventricles. Amer. F. Physiol., 137, 620 . 